\title{
ASUPAN TINGGI LEMAK DAN AKTIVITAS OLAHRAGA SEBAGAI FAKTOR RISIKO TERJADINYA HIPERTENSI OBESITIK PADA REMAJA AWAL
}

\author{
Martalina Tri K., Muhammad Sulchan") \\ Program Studi Ilmu Gizi Fakultas Kedokteran Universitas Diponegoro \\ Jl.Dr.Sutomo No.14, Semarang, Telp (024) 8453708, Email : gizifk@undip.ac.id
}

\begin{abstract}
Background : Obesity is a health problem in many countries and associated with high fat intake and lack of exercise. Obesity can lead to hypertension, through the mecanism of insulin resistance, which is known as obesity hypertension.

Objective : To analyze high fat intake and sport activity as risk factors of obesity hypertension in early adolescence. Method: The subject of this case control study consisted of 40 early adolescences with obesity hypertension as the case and 40 early adolescences without obesity hypertension as the control with equivalent age and gender in 3 junior high school in Semarang. Determining of the obesity along with percentile of BMI while determining of the hypertension along with percentile blood pressure.

Result: The prevalence of obesity hypertension in this study is 7,5\%. Bivariate analysis indicate that high fat intake is a risk factor of obesity hypertension ( $p=0.002$ : OR=4,3: $C I=1,696-11,069)$. While sport activity have significant relationship with the incidence of obesity hypertension ( $p=0.012:$ OR=3.31; $C I=1.286-8.550)$.

Conclusion : High fat intake risk4,3 times increase obesitiy hypertension in early adolescence. And sport inactivity risk 3,3 times increase obesitiy hypertension in early adolescence.
\end{abstract}

Key word: High fat intake; sport activity; obesity hypertension; early adolescence

\section{ABSTRAK}

Latar Belakang : Hipertensi obesitas menjadi masalah kesehatan di berbagai negara dan dikaitkan dengan asupan tinggi lemak dan kurangnya aktivitas olahraga. Obesitas dapat menyebabkan hipertensi, melalui resistensi insulin, yang dikenal dengan hipertensi obesitas.

Tujuan : Menganalisis asupan tinggi lemak dan aktivitas fisik sebagai faktor risiko terjadinya hipertensi obesitas pada remaja awal.

Metode : Subyek penelitian case control ini terdiri dari 40 remaja awal dengan hipertensi obesitas sebagai kasus, dan 40 remaja awal yang tidak hipertensi obesitas sebagai kontrol dengan padanan usia dan jenis kelamin di 3 SMP di Semarang. Penentuan obesitas dengan nilai persentil BMI sedangkan penentuan hipertensi menggunakan persentil tekanan darah. Asupan lemak total diperoleh dengan wawancara menggunakan FFQ semi kuantitatif. Aktivitas olahraga diperoleh dari kuesioner aktivitas olahraga.

Hasil : Prevalensi hipertensi obesitas pada penelitian ini 7,5\%. Analisis bivariat menunjukkan asupan tinggi lemak merupakan faktor risiko terjadinya hipertensi obesitas $(p=0.002: 0 R=4,3: C I=1,696-11,069)$. Sedangkan aktivitas olahraga yang rendah memiliki hubungan bermakna dengan kejadian hipertensi obesitas ( $p=0,012: 0 R=3,31)$.

Simpulan : Asupan tinggi lemak berisiko 4,3 kali meningkatkan kejadian hipertensi obesitas pada remaja awal. Inaktivitas olahraga berisiko 3,31 kali meningkatkan kejadian hipertensi obesitas pada remaja awal.

Kata Kunci: Asupan tinggi lemak; aktivitas olahraga; hipertensi obesitas; remaja awal

\section{PENDAHULUAN}

Remaja merupakan kelompok usia yang selalu ingin mencoba hal yang baru, terutama dalam pemilihan makanan. Pemilihan makanan pada masa praremaja, tidak lagi didasarkan pada kandungan gizinya tetapi sekedar sosialisi dengan teman sebayanya, untuk kesenangan dan agar tidak kehilangan status. Pada masa ini pengaruh teman sebaya lebih menonjol dari pada peran keluarga. Praremaja lebih mudah menerima pengaruh globalisasi, pengaruh pola makan "western" (eropa) dengan tinggi lemak, tinggi energi dan rendah serat menjadi makanan yang menarik.

Makanan tinggi lemak tidak memberi rasa kenyang, hanya memberikan rasa gurih sehingga menyebabkan volume makanan lebih besar supaya kenyang. Besarnya volume makanan dengan kandungan lemak tinggi, memberikan energi lebih tinggi, sehingga menjadi kendala dalam mengatur keseimbangan energi. Kecenderungan perilaku makan yang tinggi lemak akan menjadi ketidakseimbangan lemak yang akan disimpan dalam jaringan adiposa. Peningkatan jaringan 
adiposa akan meningkatkan leptin, sehingga memiliki pengaruh terhadap pengaturan keseimbangan energi dan pada akhirnya dapat menyebabkan obesitas. ${ }^{1}$

Obesitas pada anak berkaitan dengan hipertensi, diabetes mellitus tipe 2, dislipidemia, hipertrofi ventrikel kiri, masalah ortopedi dan masalah psikososial pada anak. $^{2}$ Prevalensi obesitas pada anak usia 6-17 tahun di AS dalam tiga dekade terakhir meningkat dari 7,6-10,8\% menjadi $13-14 \% .^{3}$ Prevalensi obesitas pada anak usia 6-18 tahun di Rusia adalah 10\%, di Cina adalah 3,4\%, dan di Inggris 10-17\%. Anak yang mengalami obesitas memiliki risiko 3 kali lipat menderita hipertensi dibandingkan anak yang nonobese. $^{2}$

Seiring dengan meningkatnya kejadian obesitas, dikenal sindrom metabolik yang terdiri dari obesitas sentral, resistensi insulin, hipertensi, dan dislipidemia berupa kadar trigliserida yang tinggi dan kolesterol high density lipoprotein (HDL) yang rendah. ${ }^{4}$ Sindrom metabolik terutama disebabkan oleh obesitas dan resistensi insulin. Selain sebagai tempat penyimpanan energi, jaringan lemak juga menghasilkan faktor yang menyebabkan hipertensi. Jaringan lemak dapat menguraikan angiotensin dari sitem angiotensinrenin. ${ }^{5}$ Agar tidak terjadi penumpukan energi, aktivitas olahraga diperlukan untuk membakar energi.

Pola aktivitas olahraga yang rendah dan obesitas pada anak dan remaja merupakan langkah awal terjadinya hipertensi. Penelitian yang dilakukan di Kanada menunjukkan bahwa aktivitas olahraga dapat menurunkan tekanan darah sistolik dan secara signifikan mengembalikan fungsi endotel pada anak-anak dengan kelebihan berat badan. ${ }^{6}$

Aktivitas olahraga yang rendah dan asupan tinggi lemak mempengaruhi profil metabolik dengan menurunkan tingkat asam lemak bebas dan oksidasi glukosa dalam otot skeletal dan otot jantung, yang berpotensi menimbulkan penumpukan lemak tubuh dan resistensi terhadap kerja biologis insulin. ${ }^{3}$ Pada obesitas, terjadi resistensi insulin dan gangguan fungsi endotel pembuluh darah yang menyebabkan vasokontraksi dan reabsorbsi natrium di ginjal dan menyebabkan hipertensi.

Penelitian ini bertujuan untuk mengetahui besar risiko asupan tinggi lemak dan aktivitas olahraga terhadap kejadian hipertensi obesitik pada remaja awal.

\section{METODE}

Penelitian ini termasuk dalam ruang lingkup keilmuan gizi masyarakat yang dilakukan di 5 SMP di Semarang pada bulan Mei-Juni 2012. Jenis penelitian ini adalah penelitian analitik observasional yang dilakukan dengan rancangan case control study.

Penelitian awal dilakukan untuk mengetahui prevalensi hipertensi obesitas. Populasi target dari penelitian ini adalah seluruh remaja awal usia 12-14 tahun di kota Semarang pada tahun 2012 dan populasi terjangkau adalah seluruh remaja awal usia 12-14 tahun di 5 SMP di kota Semarang. Dari 212 Sekolah Menengah Pertama yang ada di kota Semarang, dipilih 5 Sekolah Menengah Pertama dengan proporsional random samplin. ${ }^{7}$ Untuk menentukan sekolah yang akan digunakan sebagai sampel, digunakan simple random sampling. Dilakukan pengumpulan data yang meliputi identitas sampel, pengukuran tinggi badan, berat badan, lingkar pinggang, pengukuran tekanan darah dan nadi. Pengukuran antropometri tinggi badan menggunakan microtoise dengan ketelitian $0,1 \mathrm{~cm}$ dan berat badan menggunakan timbangan injak digital dengan ketelitian $0,1 \mathrm{~kg}$. Pengukuran tekanan darah menggunakan sphygmomanometer dengan ukuran manset panjang 17-19 $\mathrm{cm}$ dan lebar 7-9 $\mathrm{cm}$.

Besar sampel minimal ditentukan dengan menggunakan rumus case control berpasangan, ${ }^{7}$ dan diperoleh sampel minimal 38 untuk kasus dan 38 untuk kontrol. Pengumpulan data asupan menggunakan formulir FFQ (Food Frequency Quesioner). Persentase kecukupan lemak termasuk dalam kategori tinggi jika $>30 \%$ dari total energi dan kategori normal jika $\leq 30 \%$ dari total energi. ${ }^{8}$ Penilaian aktivitas olahraga menggunakan kuesioner aktivitas olahraga dengan metode Baecke. $^{8}$

Pengolahan dan analisis data menggunakan komputerisasi. Derajat obesitas yang dinyatakan dalam persentil $\mathrm{BB} / \mathrm{U}$ dihitung menggunakan software WHO Anthroplus. Data yang berskala numerik dideskripsikan sebagai nilai minimum, nilai maksimum, median, rerata dan standar deviasi. Data yang berskala kategorik dideskripsikan sebagai distribusi frekuensi dan persen. Analisis untuk mengetahui nilai besar risiko menggunakan uji Chi Square. ${ }^{6}$

\section{HASIL PENELITIAN \\ Karakteristik Subyek}

Hasil penelitian pendahuluan menunjukkan 355 subyek termasuk hipertensi 
(30,03\%), 155 subyek adalah obesitas $(13,11 \%)$, dan 89 anak termasuk dalam hipertensi obesitik $(7,52 \%)$.

Jumlah subyek penelitian yang terlibat dalam penelitian 40 kasus dan 40 kontrol yang telah dilakukan matching terhadap umur dan jenis kelamin. Karakteristik subyek penelitian dapat dilihat pada tabel 1.

Tabel 1. Karakteristik subyek penelitian berdasarkan usia dan jenis kelamin

\begin{tabular}{lcccc}
\hline \multicolumn{1}{c}{ Variabel } & Kasus & \multicolumn{2}{c}{ Kontrol } \\
\hline & n & \% & n & \% \\
\hline Jenis Kelamin & & & & \\
$\quad$ Laki-Laki & 27 & 67,5 & 27 & 67,5 \\
$\quad$ Perempuan & 13 & 32,5 & 13 & 32,5 \\
\hline Total & 40 & 100 & 40 & 100 \\
\hline Usia & & & & \\
12 tahun & 7 & 17,5 & 7 & 17,5 \\
13 tahun & 23 & 57,5 & 23 & 57,5 \\
14 tahun & 10 & 25 & 10 & 25 \\
\hline Total & 40 & 100 & 40 & 100 \\
\hline
\end{tabular}

Berdasarkan hasil penelitian diperoleh data rerata usia kedua kelompok 13,08 $\pm 0,656$ tahun dengan usia terendah 12 tahun dan tertinggi 14 tahun. Sebagian besar kelompok kasus dan kontrol berada pada kelompok usia 13 tahun.

BMI dan Tekanan Darah
Penentuan derajat obesitas untuk remaja dinyatakan dalam persentil $\mathrm{BB} / \mathrm{TB}$, sedangkan penentuan persentil tekanan darah disesuaikan dengan usia, jenis kelamin dan tinggi badan. Distribusi BMI dan tekanan darah dapat dilihat pada tabel 2 .

Tabel 2. Distribusi Persentil BMI dan Tekanan Darah Kelompok Kasus dan Kontrol

\begin{tabular}{lcccccc}
\hline Variabel & & $\begin{array}{l}\text { Kasus } \\
(\mathbf{n}=\mathbf{4 0})\end{array}$ & & \multicolumn{3}{c}{$\begin{array}{c}\text { Kontrol } \\
(\mathbf{n = 4 0 )}\end{array}$} \\
\hline & Rerata \pm SD & Minimal & Maksimal & Rerata \pm SD & Minimal & Maksimal \\
\hline BMI & $98,07+1,34$ & 95,3 & 99,9 & $39,22+22,64$ & 6,4 & 83 \\
\hline Tekanan Darah & & & & & & \\
Sistolik & $88,52 \pm 15,14$ & 50 & 99 & $52 \pm 8,82$ & 50 & 90 \\
Diastolik & $95,17 \pm 3,32$ & 90 & 99 & $63,25 \pm 18,86$ & 50 & 90 \\
\hline
\end{tabular}

Tabel 2 menunjukkan,rerata BMI kelompok kasus sebesar 98,07+1,34 persentil BMI, sedangkan kelompok kontrol 39,2 $\pm 22,64$ persentil BMI. Sedangkan rerata tekanan darah sistolik pada kelompok kasus sebesar $88,52 \pm 15,14$ persentil tekanan darah dan tekanan darah diastolik $95,17 \pm 3,32$ persentil tekanan darah. Rerata tekanan darah sistolik pada kelompok kontrol sebesar
$52 \pm 8,82$ persentil tekanan darah dan tekanan darah diastolik sebesar $63,25 \pm 18,86$ persentil tekanan darah.

\section{Asupan Lemak}

Proporsi lemak yang dianggap baik pada masa pertumbuhan yang optimal adalah $30 \%$ dari total kebutuhan energi.. Distribusi asupan lemak dapat dilihat pada tabel 3 .

Tabel 3. Distribusi Asupan Lemak Pada Kelompok Kasus dan Kontrol

\begin{tabular}{ccc}
\hline Asupan Lemak & $\begin{array}{c}\text { Kasus } \\
(\mathbf{n}=\mathbf{4 0})\end{array}$ & $\begin{array}{c}\text { Kontrol } \\
(\mathbf{n}=\mathbf{4 0})\end{array}$ \\
\hline Rerata \pm SD & $98,53 \pm 35,97$ & $79,67 \pm 28,75$ \\
Minimal & 26 & 38 \\
Maksimal & 186 & 152 \\
\hline
\end{tabular}


Tabel 3 menunjukkan bahwa asupan lemak pada kelompok kasus sebesar 98,53+35,97 gram. Sedangkan kelompok kontrol 79,67 $\pm 28,75$ gram.
Jika rerata tersebut dikategorikan maka hasilnya dapat dilihat dalam tabel 4.

Tabel 4. Faktor Risiko Asupan Lemak Terhadap Kejadian Hipertensi Obesitik Pada Remaja Awal

\begin{tabular}{|c|c|c|c|c|c|c|c|c|}
\hline \multirow{2}{*}{$\begin{array}{l}\text { Asupan } \\
\text { Lemak }\end{array}$} & \multicolumn{2}{|c|}{ Kasus } & \multicolumn{2}{|c|}{ Kontrol } & \multirow{2}{*}{$\mathbf{p}$} & \multirow{2}{*}{ OR } & \multicolumn{2}{|c|}{ CI $95 \%$} \\
\hline & $\mathbf{n}$ & $\%$ & $\mathbf{n}$ & $\%$ & & & Minimal & Maksimal \\
\hline Tinggi & 28 & 70 & 14 & 35 & & & & \\
\hline Normal & 12 & 30 & 26 & 65 & 0.00 & 4.3 & 1.696 & 11.069 \\
\hline TOTAL & 40 & 100 & 40 & 10 & & & & \\
\hline
\end{tabular}

Tabel 4 menunjukkan bahwa secara signifikan asupan lemak merupakan faktor risiko, karena asupan lemak yang tinggi mempunyai risiko 4,3 kali untuk menjadi hipertensi obesitik dibandingkan dengan asupan lemak yang normal $(\mathrm{p}=0.002: \quad \mathrm{OR}=4,3: \quad \mathrm{CI}=1,696-11,069)$. Tabel 4 juga didapatkan hasil bahwa pada kelompok kasus asupan lemak tinggi sebanyak $70 \%$. Sedangkan pada kelompok kontrol yang tergolong dalam asupan lemak tinggi sebanyak 35\%

\section{Aktivitas Olahraga}

Penentuan kategori aktivitas olahraga menggunakan metode baecke, dan dikategorikan menjadi 2 kategori, yaitu jarang dan sering. Hubungan dan besar risiko aktivitas olahraga dapat dilihat pada tabel 5 .

Tabel 5. Faktor Risiko Aktivitas Olahraga Terhadap Kejadian Hipertensi Obesitik Pada Remaja Awal

\begin{tabular}{|c|c|c|c|c|c|c|c|c|}
\hline \multirow{2}{*}{$\begin{array}{l}\text { Aktivitas } \\
\text { Olahraga }\end{array}$} & \multicolumn{2}{|c|}{ Kasus } & \multicolumn{2}{|c|}{ Kontrol } & \multirow{2}{*}{ p } & \multirow{2}{*}{ OR } & \multicolumn{2}{|c|}{ CI 95\% } \\
\hline & $\mathbf{n}$ & $\%$ & $\mathbf{n}$ & $\%$ & & & Minimal & Maksimal \\
\hline Jarang & 30 & 75 & 19 & 47,5 & & & & \\
\hline Sering & 10 & 25 & 21 & 52,5 & 0.01 & 3,31 & 1,286 & 8,550 \\
\hline TOTAL & 40 & 100 & 40 & 10 & & & & \\
\hline
\end{tabular}

Tabel 5 menunjukkan aktivitas olahraga jarang merupakan faktor risiko hipertensi obesitas pada remaja awal, karena aktivitas olahraga yang jarang mempunyai risiko sebesar 3,31 kali untuk menjadi hipertensi obesitas pada remaja awal $(\mathrm{p}=0.012$ : $\mathrm{OR}=3.31 ; \mathrm{CI}=1.286-8.550)$

\section{PEMBAHASAN}

Hasil penelitian dari 1186 subyek di 5 SMP di Semarang didapatkan prevalensi hipertensi sebesar $30,03 \%$, obesitas $13,11 \%$, dan hipertensi obesitik 7,52\%.

Masa remaja merupakan masa rawan terjadinya hipertensi obesitik, karena remaja cenderung memilih makanan tinggi energi, tinggi lemak, dan tinggi natrium yang merupakan manifestasi awal terjadinya hipertensi obesitik. Hasil penelitian ini menunjukkan ada perbedaan asupan lemak antara kasus dan kontrol. Subyek dengan hipertensi obesitas cenderung mengkonsumsi makanan tinggi lemak dibandingkan dengan subyek normal. Asupan tinggi lemak berisiko 4,3 kali untuk mengalami hipertensi obesitik ( $\mathrm{p}=0.002$ : $\mathrm{OR}=4,3$ : $\mathrm{CI}=1,696$ 11,069). Hasil ini sesuai dengan penelitian yang dilakukan Gregory JW pada subyek anak usia 418 tahun di London, yang menunjukkan asupan tinggi lemak berbanding lurus dengan kejadian obesitas, ${ }^{9}$ dimana obesitas dapat menyebabkan hipertensi. ${ }^{2}$

Lemak adalah cadangan energi tubuh terbesar. $^{10}$ Lemak memiliki rasa yang gurih. Densitas energi yang tinggi dimiliki oleh lemak, sehingga dapat menyebabkan keseimbangan positif dan kelebihan tersebut akan disimpan dalam jaringan adiposa. Peningkatan jaringan adiposa akan meningkatkan leptin, sehingga memiliki pengaruh terhadap pengaturan keseimbangan energi dan pada akhirnya dapat menyebabkan obesitas. ${ }^{1}$

Keadaan obesitas obesitas sentral, lemak berakumulasi sebagai lemak viseral/intraabdominal atau lemak subkutan abdomen. Obesitas sentral berisiko mengalami sindrom metabolik dan penyakit kardiovaskular, khususnya jika terdapat lemak viseral yang berlebihan. Kadar adiponektin 
yang rendah, adanya resistensi leptin, serta berbagai sitokin yang terlepas dari sel adiposa dan sel inflamasi yang menginfiltrasi jaringan lemak, menurunkan ambilan asam lemak bebas oleh mitokondria pada beberapa jaringan, menurunkan oksidasi asam lemak bebas, dan menyebabkan akumulasi asam lemak bebas intrasel. Kelebihan asam lemak bebas intraselular dan metabolik, seperti fatty acyl CoA, diacyglgycerol,dan ceramide, dapat memicu resistensi insulin, bahkan hiperinsulinemia dan hiperglikemia. ${ }^{11}$ Resistensi insulin yang disertai dengan gangguan fungsi endotel pembuluh darah, dapat menyebabkan vasokonstraksi dan reabsorpsi natrium di ginjal yang mengakibatkan hipertensi melalui penurunan nitric oxide yang menimbulkan vasodilatasi, peningkatan sensitivitas garam, dan peningkatan volume plasma. ${ }^{10,12}$

Hasil penelitian ini sejalan dengan hasil penelitian di Teheran pada wanita dewasa yang menemukan ada hubungan antara asupan tinggi lemak dengan kejadian hipertensi obesitas. ${ }^{13}$ Mereka yang sering mengkonsumsi makanan western memiliki risiko tinggi terhadap peningkatan komponen sindroma metabolik, antara lain resistensi insulin, peningkatan LDL kolesterol dan tekanan darah.

Uji chi square antara aktivitas olahraga dan kategori hipertensi obesitas menunjukkan ada hubungan yang bermakna antara kedua variabel tersebut $\quad(\mathrm{p}=0.012: \quad \mathrm{OR}=3.31 ; \quad \mathrm{CI}=1.286-8.550)$. Kelompok dengan hipertensi obesitik termasuk dalam kategori jarang melakukan aktivitas olahraga $(75 \%)$. Hal ini sesuai dengan hasil penelitian di Bantul dan Yogyakarta pada remaja SMP, dimana remaja dengan obesitas memiliki rerata aktivitas lebih rendah dibandingkan remaja non-obesitas. ${ }^{14}$

Aktivitas olahraga yang dilakukan secara teratur dapat menurunkan tekanan darah pada individu dengan hipertensi, termasuk yang mengalami obesitas. ${ }^{15}$ Peningkatan aktivitas fisik dapat menurunkan resistensi insulin, inaktivasi sistem syaraf sistemik, dan mencegah disfungsi vascular, dimana dapat menyebabkan penurunan denyut nadi dan resistensi sistem vaskular sehingga menurunkan tekanan darah. ${ }^{6}$

Penelitian yang dilakukan oleh Watts menunjukkan bahwa olahraga aerobik dapat menurunkan tekanan darah sistolik dan secara signifikan mengembalikan fungsi endotel pada anak dengan kelebihan berat remaja. ${ }^{16}$

Seseorang yang kurang melakukan aktivitas olahraga menyebabkan tubuh kurang menggunakan energi yang tersimpan dalam tubuh. Oleh karena itu, apabila asupan lemak berlebihan tanpa diimbangi dengan aktivitas olahraga yang sesuai dapat menyebabkan obesitas, dimana obesitas dapat menyebabkan hipertensi, yang dikenal dengan sindrom metabolik hipertensiobesitas.

\section{KETERBATASAN PENELITIAN}

Pada penelitian ini hanya dilakukan skrining bagi murid kelas7 dan 8. Dikarenakan kelas 9 sedang menempuh ujian nasional sehingga tidak dimungkinkan untuk dilakukan pengukuran.

\section{SIMPULAN}

1. Prevalensi hipertensi obesitik pada remaja awal adalah $7,5 \%$.

2. Besar risiko asupan tinggi lemak 4,3 kali dalam menyebabkan hipertensi obesitas pada remaja awal.

3. Besar risiko inaktivitas olahraga 3,3 kali dalam menyebabkan hipertensi obesitas pada remaja awal.

\section{SARAN}

Bagi sekolah, dapat digalakkan kegiatan "kantin sehat" yaitu kantin sekolah yang menyediakan makanan sehat dimana terdapat kerja sama antara sekolah dan ahli gizi dalam perencanaan makanan. Sehingga, konsumsi makanan tinggi lemak dapat diminimalisir untuk mencegah terjadinya keadaan obesitas.

Bagi subyek, aktivitas olahraga minimal dilakukan lima hari dengan intensitas 60 menit per hari dalam seminggu untuk mencegah disgungsi vascular pada anak dengan kelebihan berat badan, dan 90 menit per hari untuk menurunkan berat badan.

\section{DAFTAR PUSTAKA}

1 Margaret MH, June S, Neal T, Pam S, Aaron RF. Associations of Fat Distribution and Obesity with Hypertension in a Bi-ethnic Population: The ARIC Study. Obesity Research Vol. 8 No. 7 October 2000

2 Sorof J, Daniels S. Obesity Hypertension in Children; A Problem of Epidemic Proportions. Hypertension2002, 40:441-447.

3 Wang $\mathrm{O}$, Lobstein $\mathrm{T}$. Worldwide trends in childhood overweight and obesity. International Journal of Pediatric Obesity. 2006; 1: 11-25

4 WHO. Facts related to chronic disease: non communicable disease prevention and health promotion [serial online] 2003 [cited $2012 \mathrm{Apr}$ 14]. Avalaible from: http://www.who.int. 
5 Aneja A, El-Atat F, McFarlane IS, Sowers RJ. Hypertension and obesity. Diunduh dari http://rphr. endojournal.org

6 Torrance B, McGuire A, Lewanczuk R, McGavock J. Overweight, physical activity and high blood pressure in children: a review of the literature. Vascular Health and Risk Management 2007:3(1) 139-149.

7 Sudigdo Sastroatmojo, Sofyan Ismael. Dasar-dasar Metodologi Penelitian Klinis Edisi ke-2. Jakarta: Sagung Seto; 2002.

8 Baecke JAH Burema J Frijters ER. A short questionnaire for the measurement of habitual physical activity in epidemiological studies. Am J Clin Nutr. 1982; 36: 936-942.

9 Gregory JW, Lowe S: National Diet and Nutrition Survery: Young People Aged 4 to 18 Years : Report of the Diet and Nutrition Survey London, The Stationery Office.; 2000

10 Murray RK, Grammer DK, Rodwell V. Biokimia Harper. Jakarta: EGC 2009: 225-249

11 Haris S, Tambunan T. Hipertensi pada Sindrom Metabolik. Sari Pediatri 2009;11(4):257-63)

12 Vasilios K, Stella S, Sofia P, Zoe R and Gianfranco P. Mechanisms of obesity-induced hypertension. Hypertension Research (2010) 33, 386-393

13 Esmaillzadeh A, Mosug KFB, Willet W. Dietary 3. pattern, insulin resistance and prevalence of the metabolic syndrome in women. Am J Clin Nutr 2007; 85: 910-8.

14 Emy Huriyati, Hamam Hadi, Madarina Julia. Aktivitas olahraga pada Remaja SLTP Kota Yogyakarta dan Kabupaten Bantul serta Hubungannya dengan Kejadian Obesitas. Jurnal Gizi Klinik Indonesia 2004;1.

15 Hagberg JM, Park JJ, Brown MD. 2000. The role of exercise training in the treatment of hypertension: an update. Sports Med, 30:193-206.

16 Watts K, Jones TW, Davis EA, et al. 2005. Exercise training in obese children and adolescents: current concepts. Sports Med, 35:375-92. 